\title{
ENSINO REMOTO EMERGENCIAL EM TEMPOS DE PANDEMIA: PROCESSO DE METAFORIZAÇÃO PELO JORNAL FOLHA DE S. PAULO E POR PARTÍCIPES DO ERE
}

EMERGENCY REMOTE TEACHING IN PANDEMIC PERIOD: METAFORIZATION PROCESS BY THE NEWSPAPER FOLHA DE S. PAULO AND ERE PARTICIPANTS

\author{
Juliane Ferraz Oliveira ${ }^{1}$ \\ Centro Federal de Educação Tecnológica de Minas Gerais/Pontifícia \\ Universidade Católica de Minas Gerais \\ Túlio Sousa Vieira ${ }^{2}$ \\ Pontifícia Universidade Católica de Minas Gerais
}

Resumo: O objetivo do presente artigo é apresentar uma discussão sobre concepções de educação em evidência neste período pandêmico. Pretendemos flagrar metáforas que operam como grounding das concepções de Ensino Remoto Emergencial (ERE), adotadas no jornal Folha de S. Paulo e por participantes do ERE, compreendendo em que medida se distanciam e se aproximam. Para isso, adotamos como fundamentação a Teoria da Metáfora Conceptual de Lakoff e Johnson (1980[2002]), quadro que nos permitiu observar e analisar uma metáfora conceptual que subjaz aos discursos referentes ao ERE. A metodologia utilizada para seleção de dados, composição de corpus e análise é investigativa e de caráter qualitativo. Por meio das análises, pudemos identificar, enquanto resultado principal, o fato de haver uma metáfora conceptual na base do processo de conceptualização do Ensino Remoto Emergencial: ERE É MERCADORIA.

Palavras-Chave: Metáfora Conceptual; Ensino Remoto Emergencial (ERE); Educação; Pandemia.

${ }^{1}$ Endereço eletrônico: juhjuh.ferraz@hotmail.com

2 Endereço eletrônico: tuliofraga@gmail.com 
Abstract: The aim of this article is to present a discussion about conceptions of education in evidence in this pandemic period. We intend to catch metaphors that operate as grounding of the concepts of Emergency Remote Teaching adopted by media and ERT participants - to what extent they distance themselves and get closer. For that, we adopted as a foundation the Theory of Conceptual Metaphor, Lakoff and Johnson (1980[2002]), this framework allowed us to observe and analyze the conceptual metaphor that underlies the speeches regarding the ERT. The methodology used for data selection, corpus composition and analysis are investigative and qualitative. Through the analyzes, we were able to identify, as the main result, the fact that there is a conceptual metaphor at the base of the conceptualization process of Emergence Remote Teaching: ERT IS MERCHANDISE.

Keywords: Conceptual Metaphor; Emergency Remote Teaching (ERT); Education; Pandemic.

\section{INTRODUÇÃO}

O presente artigo visa a mostrar de forma comparativa como o jornal Folha de S. Paulo conceptualiza o Ensino Remoto Emergencial e como estudantes e professores da educação, que aderiram a essa prática, conceptualizam a nova modalidade de ensino. Tendo como plano de fundo a pandemia do novo coronavírus (SARS-CoV-2), um dos maiores desafios coletivos no mundo desde a gripe espanhola de $1918^{3}$, a pesquisa realizada buscou flagrar, em discursos relatados no jornal Folha de S. Paulo e em narrativas de pessoas envolvidas diretamente em práticas educacionais do regime remoto, a relação de urgência de uma prática educacional orientada como possibilidade de mitigar os efeitos da pandemia, qual seja: o Ensino Remoto Emergencial - ERE. Parece-nos possível perceber que há um engendramento nos processos de metaforização que subjazem aos discursos do jornal em comparação com discursos dos participantes do ERE.

Reconhecemos a importância de salientar que os grupos sociais, as comunidades e as populações de um modo geral não são homogêneas. Portanto, há indivíduos/classes que são particularmente vulneráveis ao período

\footnotetext{
${ }^{3}$ A este respeito: https://agora.folha.uol.com.br/sao-paulo/2020/04/apenas-a-gripe-espanholafoi-comparavel-ao-coronavirus.shtml. Acesso em: 04 ago. 2020.
} 
pandêmico. A educação está nesta situação ${ }^{4}$ e, nesse sentido, empreendemos esforços que buscaram colocar luz em problemas estruturais/primários de modo que permaneça na vanguarda a nossa lente sobre o ERE.

No Brasil, a pandemia do novo coronavírus passa a ser vista como um problema de saúde pública no final de fevereiro, com a confirmação dos primeiros casos. Medidas de afastamento e mesmo recomendações de distanciamento social passam, então, a ser adotadas em âmbitos regionais por parte de governos estaduais e municipais. Em âmbito nacional, no dia 17 de março de 2020, o Ministério da Educação (MEC) lança a portaria $n^{0}$ 343, que autoriza a substituição de aulas presenciais em Instituições de Ensino Superior:

Art. $1^{o}$ Fica autorizada, em caráter excepcional, a substituição das disciplinas presenciais, em andamento, por aulas que utilizem meios e tecnologias de informação e comunicação, por instituição de educação superior integrante do sistema federal de ensino, de que trata o art. $2^{\text {o }}$ do Decreto $\mathrm{n}^{-}$9.235, de 15 de dezembro de 2017 (BRASIL, 2020).

No contexto da implementação de um novo regime letivo, nem todas as instituições de ensino tiveram as mesmas condições de aplicação de modalidades que contemplassem, total ou prioritariamente, meios digitais de interação. Recortes socioeconômicos deveriam ser pensados, além da adequação pedagógica desses novos modos de interação, para que não fossem somente compreendidos em termos de transposição integral, completa e sem quase nenhuma reformulação do regime presencial para o regime remoto. Nesse sentido, com o intuito de pensarmos definições sobre o que seja o regime remoto de educação, nos afiliamos aos termos de Hodges et al (2020) a respeito do ERE:

${ }^{4}$ Dados do IPEA (Instituto de Pesquisa Econômica Aplicada), em 02/09/2020, revelam que "seis milhões de estudantes brasileiros, da pré-escola à pós-graduação, não dispõem de acesso domiciliar à internet em banda larga ou em rede móvel 3G/4G para acompanhar aulas e outras atividades online". Os dados ainda apontam que 96\% desses estudantes são oriundos de escolas públicas. Disponível em: https://www.ipea.gov.br/portal/index.php?option=com_content\&view=article\&id=36560\&cat id=10\&Itemid=9. Acesso em: 07 ago. 2020. 
Em contraste com as experiências que são planejadas desde o início e projetadas para serem online, o Ensino Remoto Emergencial (ERE) é uma mudança temporária de ensino para um modo alternativo devido às circunstâncias da crise. Envolve o uso de soluções de ensino totalmente remotas para instrução ou educação que, de outra forma, seriam ministradas presencialmente ou mesclados ou como cursos híbridos e que retornariam a esse formato assim que a crise ou emergência diminuísse. $O$ objetivo principal nessas circunstâncias não é recriar um sistema educacional robusto, mas, sim, fornecer acesso temporário ao ensino e suporte educacional de uma maneira que seja rápida de configurar e esteja disponível de forma confiável durante uma emergência ou crise. Quando entendemos o ERE dessa maneira, podemos começar a separá-lo do "aprendizado online". 5 (HOGDES et al., 2020, n.p).

À luz dessa compreensão, assumimos que a concepção de educação presencial que colocamos à baila neste artigo se configura como processo ${ }^{6}$ : interação e engajamento de atenção do aluno; processo em que se subentende empatia, ensino e aprendizagem. Essa concepção adotada não anula o fato de que, principalmente nos últimos anos, a educação vem sendo cada vez mais mercantilizada. Ainda que não nos propusemos a discutir os graves sinais de que a educação tem se tornado um produto rentável, reconhecemos que o contexto pandêmico, que traz em seu bojo medidas de readequação do modelo de ensino, poderia significar um recrudescimento dos usos de regras e moldes de mercado no ambiente educacional.

\footnotetext{
${ }^{5}$ Tradução livre de: "In contrast to experiences that are planned from the beginning and designed to be online, emergency remote teaching (ERT) is a temporary shift of instructional delivery to an alternate delivery mode due to crisis circumstances. It involves the use of fully remote teaching solutions for instruction or education that would otherwise be delivered faceto-face or as blended or hybrid courses and that will return to that format once the crisis or emergency has abated. The primary objective in these circumstances is not to re-create a robust educational ecosystem but rather to provide temporary access to instruction and instructional supports in a manner that is quick to set up and is reliably available during an emergency or crisis. When we understand ERT in this manner, we can start to divorce it from "online learning." (HODGES et al., 2020, n.p).

6 Freire (1967) discorre a respeito do papel criativo e libertador da educação. Nesse entendimento, concordamos com o autor e destacamos que o processo dialético-dialógico do Eu só se configura em relação ao outro. A premissa básica para que ocorra sentido, ocorra interação, criatividade no ensino e na educação é um processo que abranja as intersubjetividades do Eu e do outro.
} 
O conjunto de dados mapeados sinalizou uma robustez, tanto nas narrativas dos partícipes quanto nos dados relatados no jornal Folha de S. Paulo, da seguinte metáfora conceptual: ERE É MERCADORIA. Essa concepção mercadológica concebe o processo de ensino em termos de um produto precificável. Assim, ao que parece, pudemos analisar a produtividade de uma metáfora que, provavelmente, diverge daquela que é mobilizada quando falamos em educação presencial, já que o fazemos em termos de processo, sendo esta uma metáfora que reflete interações sociais diversas.

Um outro fator que percebemos é que o termo EAD (Educação a Distância), que apareceu nos discursos dos sujeitos que aderiram ao ERE e nos enunciados do jornal em pauta, não é equivalente ao ERE, dado que a Educação a Distância não se configura - especificamente - para necessidades e mudanças emergenciais num período com limitações e suporte escasso. A EAD debruça-se em projetos e compromissos ajustados ao ambiente de aprendizagem virtual, construído para uma demanda específica a distância. Keegan (1991) elenca elementos que considera centrais na Educação a Distância, entre eles: a) separação física entre professor e aluno; b) influência da organização educacional (planejamento, sistematização, plano, projeto, organização dirigida etc.); c) uso de meios técnicos de comunicação e d) possibilidade de encontros ocasionais com propósitos didáticos e de socialização. Não há relação comparativa entre ambas as instâncias, nem possibilidade de serem concebidas uma pela outra, pois o ERE está ocorrendo em primeira mão, reflexões estão se sistematizando online, em uma experienciação fenomenológica.

Afirmamos que o objetivo deste artigo não foi contrapor o ERE entre instituições privadas e públicas de ensino. Entretanto, é preciso dizer que estas foram/estão sendo gravemente afetadas, já que são regidas pela lógica da isonomia. Assim, se um dos estudantes não consegue ter acesso digital satisfatório não é possível que se imponha este regime sem que se corrija certas 
desigualdades. Em relação às instituições particulares, especificamente, o que vimos foram implementações apressadas, sem se refletir sobre essa nova lógica de interação a contento.

Frente a esse cenário, elegemos como objeto de análise o processo de metaforização subjacente ao discurso do jornal Folha de S. Paulo em comparação com os discursos de estudantes e professores que aderiram ao ERE. Para isso, traçamos como objetivos de escrita: apresentar uma discussão sobre concepções de educação que estão em evidência neste período pandêmico à luz dos fundamentos teórico-metodológicos; flagrar metáforas que operam como grounding das concepções de Ensino Remoto Emergencial adotados pelo jornal Folha de S. Paulo e pelos participantes do ERE, percebendo em que medida se distanciam e se aproximam.

Justificamos o trabalho em voga pelo fato de 1) colocar em evidência temáticas que se relacionem com a pandemia do novo coronavírus (SARS-CoV2), um dos grandes marcos da história recente, espaço privilegiado nas discussões e produções científico-acadêmicas neste ano. Acreditamos que tentar compreender o momento em que se vive, a partir de parâmetros metodológicos bem estabelecidos, seja de extrema relevância. Assim, o recorte temporal dos dados do domínio jornalístico ${ }^{7}$, entre 15 e 31 de março de 2020, tem ancoragem histórica.

2) Além disso, é preciso entender as particularidades que cercam o ERE e quais são as consequências de sua operacionalização por um período excepcional. Os dados se estruturam em termos de projeção (como se), e a natureza distinta dos textos é justificada na virtualização. Portanto, avaliar dados de naturezas diferentes nos permitiu flagrar um problema, oferecendo, na lente

\footnotetext{
7 Os dados levantados para a análise deste trabalho fazem parte de um corpus maior que constituímos em espaços-temporais distintos desde o início da pandemia do novo coronavírus. Tendo em vista as restrições protocolares para a feitura deste artigo, optamos por operacionalizar um recorte histórico que será objeto da análise.
} 
desta investigação, um argumento sólido que permitiu comparar o dado de natureza relatada com o dado de natureza vivida.

3) É importante observar também a produtividade da metáfora na vida cotidiana, já que o uso pervasivo é uma das principais marcas das metáforas conceptuais $^{8}$. Por meio da análise comparativa, esperamos compreender como a metáfora foi mobilizada, sinalizando que conceptualizar o ERE como mercadoria estruturou as experiências e discursos frente a essa modalidade.

Por fim, julgamos necessário 4) descrever para entender o ERE, pois, como vimos, ele ainda nos acompanhará por algum tempo, dado que os efeitos da pandemia durarão por um período longo em nosso país, já que medidas que se relacionam diretamente a atenuação do problema não foram aplicadas de maneira precisa ${ }^{9}$.

\section{FUNDAMENTAÇÃO TEÓRICA}

Neste artigo, assumimos um quadro teórico que privilegia o estudo da metáfora e do processo de metaforização sob o viés dos Estudos de Linguagem e Cognição. Para isso, privilegiamos uma teoria que verticaliza as discussões acerca desse fenômeno: a Teoria da Metáfora Conceptual. A Teoria da Metáfora Conceptual (TMC) proposta em 1980, por Lakoff e Johnson, a partir da obra "Metaphors We Live By", Metáforas da Vida Cotidiana, foi um divisor de águas para os estudos da Linguística Cognitiva (LC). De antemão, é importante salientar que Lakoff e Johnson detalham e operam pontualmente com uma

8 De acordo com Lakoff e Johnson (2002), o conceito metafórico é sistemático, ou seja, a linguagem utilizada para falar sobre determinados conceitos é metafórica. Nas palavras dos autores: “Uma vez que expressões metafóricas em nossa língua são ligadas a conceitos metafóricos de uma maneira sistemática, podemos usar expressões metafóricas linguísticas para estudar a natureza de conceitos metafóricos e, dessa forma, compreender a natureza de nossas atividades". (LAKOFF; JOHNSON, 2002, p. 50).

9 "Em rede nacional, Bolsonaro critica fechamento de escolas e comércio e compara coronavírus com 'resfriadinho'". Disponível em: https://www.bbc.com/portuguese/brasil52028945. Acesso em: 08 ago. 2020. 
concepção-outra de metáfora, originalmente proposta por Reddy (1979), em Conduit Metaphor, Metáfora do Canal (ou Conduto). Para Lakoff e Johnson, a linguagem é compreendida em termos de processamento mental que faz emergir funções de organização conceptual do viver, do acontecimento produzir sentido no nicho bio-sócio-cultural humano, apresentando um salto nas pesquisas ancoradas nessa perspectiva teórica.

A partir de Lakoff e Johnson, a metáfora apresentou nova roupagem, não mais como tropo, e sim como manifestação do pensamento. Linguagem, pensamento e ação são organicamente metafóricos. Tratam-se de expressões de estruturas conceptuais subjacentes às atividades humanas. Para os teóricos, são projeções ancoradas num domínio-fonte, compreendido em temos mais concretos, e num domínio-alvo, compreendido em termos mais abstratos. Assim, podemos dizer que a metáfora organiza/categoriza as experiências em nível motor do ser humano a partir de um universal antropológico. As projeções são, então, expressões metafóricas em níveis: i) Metáforas linguísticas, variadas e presentes no arcabouço das línguas; e ii) Metáforas conceptuais, mapeamentos ontológicos e epistêmicos entre domínios conceptuais, que emergem operacionalmente no léxico e na gramática. ${ }^{10}$

A metáfora é, para a maioria das pessoas, um recurso da imaginação poética e um ornamento retórico - é mais uma questão de linguagem extraordinária do que de linguagem ordinária. Mais do que isso, a metáfora é usualmente vista como uma característica restrita à linguagem, uma questão mais de palavras do que de pensamento ou ação. Por essa razão, a maioria das pessoas acham que pode viver perfeitamente bem sem a metáfora. Nós descobrimos, ao contrário, que a metáfora é generalizada na vida cotidiana, não apenas na linguagem, mas no pensamento e na ação. Nosso sistema conceptual ordinário, em termos do que todos nós pensamos e agimos, é fundamentalmente metafórico por natureza (LAKOFF; JOHNSON, 2002, p. $45)$.

${ }^{10}$ Concordamos com Lakoff e Johnson (1980) acerca das metáforas, que são um fenômeno natural, apontando a metáfora conceptual como parte orgânica do pensamento humano e a metáfora linguística como parte natural da linguagem humana. Metáforas linguísticas, preexistentes no sistema sensório-perceptivo humano, flagram/revelam as metáforas conceptuais. 
No horizonte da metáfora conceptual, Lakoff e Johnson lançam exemplos como "VIDA É VIAGEM"; “DISCUSSÃO É GUERRA”. Nas asserções, o domínio envolve correspondências que podem ser lidas como $X$ é $Y$. Tais correspondências, podem ser tanto ontológicas quanto epistêmicas. De acordo com a TMC, conceptualizamos domínios em que metáforas conceptuais se manifestam e estão em disposição numa rede de sentidos, numa hierarquia organizacional. Nessa seara, compreendemos a teoria a partir de uma motivação experiencial corporificada, embodiment. Isso significa dizer que a concepção de metáfora sustentada pelos autores é fundamentada na experiência corpórea, conceptualizada na estrutura sensório-perceptual motora do ser humano.

o conhecimento da realidade, tenha sua origem na percepção, na linguagem ou na memória, precisa ir além da informação dada. Ela emerge da interação dessa informação com o contexto no qual ela se apresenta e com o conhecimento preexistente do sujeito conhecedor. A orientação geral de que o mundo objetivo não é diretamente acessível, mas sim construído a partir de influências restritivas do conhecimento humano e da linguagem (LAKOFF; JOHNSON, 1980, p. 13).

Ancorados na concepção de embodiment, conseguimos operar por esquemas imagéticos, ou seja, estruturas arquitetônicas baseadas em padrões de ação humana: perceber, atentar, memorar. Trata-se de um conjunto de habilidades gerais e sensório-perceptivas em interação num nicho bio-sócio-cultural. Pela importância da teoria e sua operosidade para estudos no campo da LC, optamos por utilizá-la como principal fundamento desta investigação. A partir dela, viabilizamos uma leitura produtiva dos dados selecionados, já que nos possibilita flagrar, por meio dos usos linguísticos, metáforas que estruturam nossas ações e relações com determinados fenômenos abstratos e complexos. Vejamos.

É preciso dizer que, quando compreendemos algo em termos de outro, mais do que falarmos sobre algo como se fosse outra coisa, nós estruturamos as ações que realizamos para a compreensão do primeiro fenômeno em termos do segundo. Assim, não precisa necessariamente que um tropo linguístico, no 
sentido tradicional do que seja metáfora, seja identificado, antes disso, as bases que fundamentam a compreensão desse determinado fenômeno são metafóricas. Nesse sentido, parafraseando os autores, a metáfora não se encontra nas palavras, mas no próprio conceito.

Quando dizemos que o Ensino Remoto Emergencial é tratado em termos de mercadoria no período pandêmico, demonstramos um tipo de estruturação metafórica diferente daquela que compartilhamos sobre educação em momentos não pandêmicos. Nesse momento, estamos afirmando que aquilo que pode ser conceptualizado em termos de processo passa a ser conceptualizado em termos de produto precificável. Isso significa dizer, então, que, neste período de distanciamento social, por conta da pandemia do novo coronavírus, culturalmente, o Ensino Remoto Emergencial pode ser compreendido da seguinte maneira: a) não ser colaborativo - construção individual do conteúdo por parte do professor; b) os sujeitos recebem os conteúdos formatados prontos produto acabado; c) os professores nem sempre sabem se os alunos estão engajados na aula, já que câmeras e microfones constantemente ficam desligados - nível de atenção conjunta; d) aprendizado em uma perspectiva passiva e não gradual - formatação de um modelo único de aula; e) encontros não presenciais - virtuais etc.

Dizer que a compreensão de certos conceitos e eventos é metaforicamente constituída significa dizer que existem aspectos que são iguais e aspectos que são diversos no momento da produção metafórica, senão não seria uma relação metafórica, mas de equivalência. “[...] quando dizemos que um conceito é estruturado por uma metáfora, queremos dizer que ele é parcialmente estruturado e que ele pode ser expandido de algumas maneiras e não de outras." (LAKOFF; JOHNSON, 2002, p. 57).

Nessa perspectiva cognitiva, as metáforas são primeiramente matéria do pensamento e só depois da linguagem. Um dos pontos mais importantes 
apresentados pelos autores é de que a metáfora não é unicamente uma questão linguística, como palavras sendo compreendidas por seu próprio significado. Essa perspectiva vai ao encontro de um pressuposto, caro a esta análise, de que objetos, coisas ou mesmo palavras não possuem significado que não o atribuído pelo ser humano no momento da construção do sentido, compreendida em uma perspectiva bio-sócio-cultural. Sabendo, então, que, de acordo com a TMC, os processos de pensamento humano são, em grande parte, metafóricos, resta claro que o sistema conceptual humano é metaforicamente estruturado e definido.

Nesse contexto, assumimos o compromisso de rastrear quais metáforas subjazem à experiência dos estudantes e professores comparativamente a enunciados do jornal Folha de S. Paulo durante o chamado Ensino Remoto Emergencial. Como pontuado anteriormente de maneira breve, nos tratos preliminares dos dados, pudemos perceber que há uma metáfora recorrente: ERE É MERCADORIA. Por isso, nos deteremos na leitura crítica dos dados a partir desse mote de análise.

\section{MATERIAIS E MÉTODOS}

A presente pesquisa busca oferecer uma análise qualitativa de relatos e narrativas sobre o ERE e tem como mote apresentar uma reflexão sobre educação e ensino à luz da LC. Para tanto, arregimentamos a busca dos dados jornalísticos no jornal Folha de S. Paulo ${ }^{11}$ (em 10/07/2020), em espaço-tempo focalizado nos dias 15 e 31 de março de 2020 em sua plataforma online, na ferramenta "buscar" do próprio site, um ícone para pesquisa de temas/conteúdos variados, que pode ser visualizado na forma de uma lupa, amparados por um recorte com as seguintes

${ }^{11}$ A Folha de São Paulo configura-se como o maior jornal do Brasil, vide nota do próprio veículo: https://www1.folha.uol.com.br/poder/2020/06/maior-jornal-do-brasil-folhaconsolida-crescimento-digital.shtml. Acesso em: 09 jul. 2020. No período pandêmico, em abril deste ano, o jornal recebeu mais de 73 milhões de visitantes únicos em sua plataforma online, dados relatados no jornal segundo a Google Analytics. 
palavras-chave: educação; ensino; pandemia. De um total de 539 notícias relacionadas diretamente ao recorte de pesquisa, optamos, dada a factibilidade de trabalhar o corpus, por selecionar 2, compreendidas especificamente nos dias 26 e 31/03. A escolha baseou-se no próprio algoritmo do jornal, que capta e apresenta as notícias principais e mais vistas em sua grade na página inicial dos resultados. A partir disso, foi possível visualizar notícias que projetavam o Ensino Remoto Emergencial (ERE).

Num segundo momento, optamos por construir um outro corpus baseado em textos escritos a partir de uma provocação - um questionário sucinto -, uma experiência de produção escrita dos participantes que aderiram ao ERE, de modo que pudéssemos flagrar nessas narrativas a conceptualização sobre o acontecimento em voga. Assim, apresentamos o seguinte quadro:

Quadro 1 - Questionário ERE.

1. A partir da sua experiência de estudos/trabalhos na modalidade remota, em meio aos eventos desencadeados pela pandemia da Covid-19, construa uma narrativa inspirada na seguinte frase: "Diante do cenário da pandemia do coronavírus e da implementação do Ensino Remoto Emergencial, se eu pudesse..."; e

2. Sobre condições infraestruturais e instrumentais para acesso às aulas, aos conteúdos e para interações em ambientes virtuais, como você classificaria sua experiência? Descreva o ambiente de estudos/trabalho (se há um espaço específico para trabalho/estudo), equipamentos utilizados por você (computador, celular, tablet, televisão etc.) e qualidade de internet (instável/estável, permite acesso satisfatório ou não) no acesso às aulas/interações digitais.

Fonte: próprios autores.

A experiência com o formulário foi disponibilizada entre os dias 20/07/2020 e o dia 02/08/2020 por meio da plataforma Google Forms, sendo divulgada nos e-mails de grupos de estudos e em grupos virtuais de alunos vinculados a instituições de Ensino Superior, e reuniu um conjunto total de 18 respostas, sendo elas 15 de alunos de pós-graduação (mestrado e doutorado), 1 de graduação e 2 professores de ensino básico (médio e fundamental). Ao final do período estipulado, todas as respostas do questionário foram selecionadas para o desenvolvimento do processo analítico. 
Em relação a faixa etária dos sujeitos participantes, constatamos uma variação entre 20 e 60 anos de idade, predominando respostas de pessoas com mais de 30 anos. A partir disso, foi possível empreender esforços e operar comparativamente para sinalizar aquilo que a Folha de S. Paulo projetava para o ERE e aquilo que as narrativas dos sujeitos partícipes revelam sobre essa experiência, suscitando se aquilo que era da ordem da projeção se espelhava ou não na experiência vivida por estudantes e professores.

Considerando que este é um estudo que vem para contribuir e sistematizar reflexões que estão ocorrendo em primeira mão, em caráter inédito, o caráter exploratório pode favorecer e potencializar novas pesquisas.

\section{APROXIMAÇÃO ANALÍTICA}

De um modo geral, compreendemos que as práticas sociais e de linguagem se constituem reciprocamente. As consequências metodológicas disso sugerem que é indispensável pensar a produção de sentidos com essa dinâmica na base das interações. Assim, participantes, ao conceptualizarem o ERE, constroem práticas sociais e de linguagem, fazendo emergir narrativas históricas sobre a experiência vivida, o acontecimento pandemia do novo coronavírus (SARS-CoV-2). O recorte da investigação que fazemos dá conta de textos instituídos em momentos diferentes, espaços-tempo outros em que a produção de sentidos refrata e nos possibilita anunciar que a projeção do jornal em questão e a projeção de estudantes e professores que aderiram ao ERE possuem processamentos metafóricos que se assemelham em determinados momentos de seus relatos e narrativas, os discursos em comparação.

Jornais, via de regra, reportam ou noticiam dados de realidade. Interpretam aquilo que está observado na vida social, o que pensamos ou algo que deva ser objeto de reflexão. Como tratamos de dados que se estruturam, do ponto de vista discursivo-cognitivo, em forma de projeções que remetem a 
variáveis distintas, ao estabelecermos comparação, é possível notar que as notícias trabalham e pressupõem - metodologicamente - dado contrafactual. $\mathrm{O}$ primeiro recorte ${ }^{12}$ analítico que iremos demonstrar revela uma narrativa do jornal ancorada no discurso relatado. Vejamos alguns exemplos de relatos coletados pelo jornal Folha de S. Paulo e incluídos na matéria:

Quadro 2 - Notícia 1

\section{Jornal: Folha de S. Paulo}

Data: $31 / 03 / 2020$

Título da notícia: "60\% das universidades federais rejeitam ensino a distância durante quarentena"

Relato 1: "É uma proposta de substituição muito frágil e irresponsável diante da estrutura e condições que as universidades enfrentam. O problema mais grave é a falta de acesso dos alunos, mas há ainda outras questões, como a falta de equipamentos para os professores, de plataformas e licença de programas para atividades em uma escala tão grande". Presidente da ANDES (Sindicato Nacional dos Docentes das Instituições de Ensino Superior)

Relato 2: "Àqueles que não disponham de estrutura e conexão restaria buscar apoio junto a familiares e colegas ou mesmo se dirigir a uma lan house, o que violaria as regras de isolamento". Reitoria UFPE (Universidade Federal de Pernambuco)

Fonte: https://www1.folha.uol.com.br/educacao/2020/03/60-universidades-federais-rejeitamensino-a-distancia-durante-quarentena.shtml Acesso em: 10 jul. 2020.

Santos (2013), em trabalho de dissertação na Universidade Federal de Minas Gerais/UFMG, investigou o ensino e aprendizagem da língua inglesa e apresentou a seguinte metáfora conceptual: APRENDIZAGEM DE INGLÊS É FINANÇAS. Na ótica da autora, o processo educacional é conceptualizado metaforicamente como algo de "valor", como um "negócio" que engaja a relação entre professor e aluno. Em outras palavras, a relação de ensino é tomada como aquisição/ganho e, ainda, o aluno é entendido tal qual um investidor financeiro.

12 Disponível em: https://www1.folha.uol.com.br/educacao/2020/03/60-universidadesfederais-rejeitam-ensino-a-distancia-durante-quarentena.shtml. Acesso em: 10 jul. 2020. 
Na esteira do discurso relatado, vide Quadro 2, há um entendimento emergente de que não há outro fim senão a realidade apresentada pela Folha, a rejeição dessa modalidade configurada no jornal como ensino a distância. A narrativa jornalística apresenta uma constatação daquilo que não existe: "falta de acesso dos alunos"; "falta de equipamentos para os professores"; "de plataformas e licenças de programas para atividades" etc.

O que flagramos no Quadro 2 é que o jornal conceptualiza o ERE, a partir de relatos instituicionais, em termos de uma experiência negativa. A quebra da expectativa de ensino presencial - operacionalizado face a face entre professor e aluno -, apresenta uma variável ruim, já que o elemento presença é aparentemente o elemento criativo, conditio sine qua non para aprender. As narrativas que projetam o ERE, "uma proposta de substituição muito frágil e irresponsável", definem-no como aquilo que ele não é, aquilo que ele não se possui e insinuam um enlace financeiro imbricado entre partícipes e ERE, como se nota no Relato 2. Se o estudante ou professor não possuir as ferramentas mínimas necessárias, caberia buscar aporte com parentes e/ou colegas, de modo que pudesse fazer parte do ERE. Excluída essa possibilidade, restaria, por fim, se dirigir a uma lan house, o que converteria em outro investimento para o acesso. Sem essa última hipótese, ainda que infringindo a exigência de distanciamento social, o sujeito ficaria, de fato, sem alternativas, ou seja, sem aprender. Em outras palavras, a atualização daquilo que seria o processo de ensino e aprendizagem, um processo de interação conjunta entre o eu e o outro, uma dinâmica humana que difere daquela que é estabelecida na modalidade remota, ou seja, a possibilidade de troca de conhecimentos, de crescimento compartilhado, é substituída pelo entendimento de que somente com um investimento financeiro é possível desfrutar/participar dessa modalidade de ensino. Assim, evidenciamos que as expressões que conceptualizam o ERE em termos precificáveis - buscar apoio (financeiro) com familiares e colegas; pagar acesso à 
internet em uma lan house; adquirir plataformas e licenças de programas; investir em estrutura - colocam em evidência a metáfora ERE É MERCADORIA.

A produtividade da metáfora favorece o entendimento de que aquilo que falta no processo de ensino e aprendizagem é meramente uma questão de compra. Se não tem acesso, compra-se (aprendizagem) e está contemplado (aprendido). Com foco em outra notícia veiculada pela Folha de S. Paulo ${ }^{13}$, analisaremos mais alguns trechos do discurso relatado pelo jornal.

Quadro 3 - Notícia 2.

\section{Jornal: Folha de S. Paulo}

Data: $26 / 03 / 2020$

Título da notícia: “Pais com filhos em escolas de elite pedem redução de mensalidades durante quarentena"

Relato 1: "O pagamento é parte da obrigação contratual assumida pelos responsáveis e é condição para que os alunos tenham direito à reposição". Secretaria Nacional do Consumidor

Relato 2: "É de se esperar que a escola tenha uma redução de custos e despesas variáveis durante o período de crise, tais como iluminação, energia elétrica e materiais em geral”. Nota em documento assinado por 555 pais de alunos

Relato 3: “Tenho explicado aos pais que nossos custos não caíram. Na verdade, aumentaram, com os investimentos em tecnologia, as horas extras que os funcionários estão fazendo para oferecer uma estrutura completamente nova. Se reduzirmos o valor, vamos ter que demitir pessoal, o que seria um absurdo, uma irresponsabilidade neste momento". Diretor de escola particular

Relato 4: “É natural essa preocupação, e as pessoas acham mais fácil negociar com a escola, onde têm contato direto com o diretor, com o pessoal do financeiro. É diferente de uma prestação de carro ou apartamento. Mas, se reduzirmos, vamos quebrar o colégio". Diretor de escola particular.

Fonte: https://www1.folha.uol.com.br/educacao/2020/03/pais-com-filhos-em-escolas-de-elitepedem-reducao-de-mensalidades-durante-quarentena.shtml Acesso em: 10 jul. 2020.

Os dados anteriormente expostos concebem a metáfora conceptual, colocada à baila neste artigo, e operacionaliza a noção de ordem mercadológica,

13 Disponível em: https://www1.folha.uol.com.br/educacao/2020/03/pais-com-filhos-emescolas-de-elite-pedem-reducao-de-mensalidades-durante-quarentena.shtml. Acesso em: 10 jul. 2020. 
que organiza e ajusta a concepção de ensino e educação ao deslocar a lógica do processo/do conhecimento co-construído para a proposição de produto a ser adquirido. Os dados esquemáticos, nessa ordem, dão pistas de que podem ser compreendidos como realidade, como acontecimento. Tangencialmente a essa concepção, o modo como o jornal sinaliza a noção de ERE vai ao encontro daquilo que é da ordem do acabado/pronto, que basta comprar/adquirir para ser experenciado como ensino, como educação.

O Relato 1, da Quadro 3, em "o pagamento é parte da obrigação contratual assumida pelos responsáveis e é condição para que os alunos tenham direito à reposição", permite-nos inferir que a relação de dependência instaurada sugere que as práticas educacionais instituídas possuem uma base primitivamente financeira. ERE, ao contrário do que se espera, um modelo emergencial com vistas a mitigar os efeitos da crise pandêmica, suscita uma concepção porosa, de comercialização, de mercantilização da educação em modalidade remota. Aqueles que não possuem acesso, não desfrutam de condições mínimas necessárias para arcarem com a financeirização da prática educacional - obrigatoriamente - perderão o direito ao consumo do produto educação, o que amplia de forma vertical as desigualdades sociais em âmbito nacional.

A partir dos Relatos 2 e 3, do Quadro 3, podemos observar um choque de interesses econômicos. O que se esperaria como projeto de base, aquele em que partimos do pressuposto de que a educação é um processo dinâmico, integrado e culturalmente vital para a formação de identidades, é marcado pela financeirização da educação. "Redução de custos e despesas variáveis" vão de encontro a "investimentos em tecnologia; às horas extras que os funcionários estão fazendo". Nessa ótica, destacamos novamente a metáfora ERE É MERCADORIA. Ainda que sob perspectivas conflitantes, de pais e de escolas, a transposição de educação, atividade pedagógica, para mercadoria a ser adquirida, sinaliza uma interseção mercadológica: na exigência da redução do custo-educação; na 
justificativa do investimento financeiro em bens e serviços que possibilitem o acesso na modalidade remota. ERE É MERCADORIA reorganiza a concepção de educação nos relatos do jornal neste período pandêmico.

O último relato aponta mais um fato grave. Em "é natural essa preocupação, e as pessoas acham mais fácil negociar com a escola, [...]" e "é diferente de uma prestação de carro ou apartamento", apontamos um acirramento estreito nas concepções precificáveis de educação. Se outrora a educação era tomada como mercadoria, o que já apresenta conceptualizações de valências negativas, no Relato 4, ela é conceptualizada em termos de mercadoria de pouco valor, sendo subutilizada/subjugada em comparação a possíveis negócios mais vindouros e de tratos mais complexos tais como a compra de um veículo ou bem imóvel. À medida que essa pressuposição, educação em tempos remotos é, necessariamente, uma mercadoria barata, de valor questionável, vem à tona, reconhecemos que as projeções sociais a respeito daquilo que poderia se conceptualizar sobre o ERE como uma experiência de cunho positivo e compartilhado é silenciado. Isso reflete a forma como socialmente está sendo concebido o ERE, algo imaterial, pouco palpável, que, em uma sociedade que preza pelo acúmulo, vale menos do que bens materiais.

Assim, a metáfora ERE É MERCADORIA carrega/modela consequências dissonantes em comparação à concepção de educação como processo, que se estrutura por meio de interações presenciais com compartilhamento do mesmo espaço físico, bem como contato gestual e visual, além de engajamento atencional de outra ordem, promovendo uma outra perspectiva educacional que não a de produto.

Trabalhar com textos de searas diferentes pressupõe detalhes de uma experienciação bio-sócio-cultural que só podem ser rastreados a partir da própria experiência em si (ERE). Em outras palavras, a incorporação da representação a respeito do ERE só encontra ecos ou dissonâncias naquilo que o jornal Folha de S. 
Paulo projeta se e somente se os participantes que aderiram ao ERE confirmam ou refutam os dados levantados na ordem da projeção operacionalizada pelo jornal. Nessa direção, abordaremos os dados levantados pelo corpus dos estudantes e professores que aderiram ao ERE, mantendo como foco a possibilidade de aproximação ou distanciamento em comparação com as marcas flagradas nos discursos relatados pela Folha de S. Paulo. Parece-nos que é possível compreender que a metáfora que estrutura o discurso do jornal em estudo e dos estudantes e professores que aderiram ao ERE é a mesma, ainda que possa haver variáveis.

É importante ressaltar que o fato de trabalhar com o quadro da metáfora conceptual exige-nos empenho em observar a pervasividade de uma metáfora, ou seja, perceber se há utilização massiva e disseminada de certas construções metafóricas. Como estudantes e professores, que aderimos ao Ensino Remoto Emergencial, nossa percepção subjetiva e intuição permitiram-nos crer que existem certas consistências no processo de conceptualização dessa modalidade de ensino. Assim, no início desta investigação, ainda que naquele momento de forma preliminar e incipiente, conseguimos perceber que há variados pontos de encontro em relação às experiências de nossos colegas, conhecidos e desconhecidos (acessados por meio de notícias, reportagens, depoimentos etc.) e o discurso relatado pela Folha de S. Paulo. Algumas dessas coincidências dizem respeito à forma como o Ensino vem sendo estruturado em tempos de pandemia. Vale a pena um parêntese para dizer, neste momento, que a via digital é o principal meio de acesso à educação, mas não somente desta, como também de trabalho, entretenimento e, em certos casos, saúde etc.

Mesmo que a proposta não seja traçar um paralelo entre a educação presencial e o ensino remoto, um contraponto se impõe, pois, em estado regular de normalidade, os nossos parâmetros daquilo que seja educação e ensino são diferentes daqueles que vêm sendo construídos a partir da imposição da 
modalidade remota em regime emergencial, desde o início da pandemia e deflagração do isolamento social. Um primeiro elemento que deve ser observado é que o ensino por vias digitais era considerado exceção e ocorria sempre com um planejamento prévio e concordância com o modelo de ensino a priori a contratação do serviço. Outro ponto importante é que grande parte do ensino virtual era proposto e disponibilizado por instituições particulares. Um terceiro aspecto é que essa modalidade de ensino mediado por tecnologias digitais não abrangia o ensino básico ( $1^{\underline{o}}$ ano do Ensino Fundamental à $3^{\underline{a}}$ série do Ensino Médio). O que fica evidente, a partir dessa exposição, é que o cenário atípico mexe com estruturas já assentadas do sistema educacional, grandes desafios e dificuldades quanto ao acesso, à manutenção da qualidade, ao nível de participação em aula (engajamento atencional) etc.

Agora, trataremos das narrativas coletadas por meio de formulário, conforme já expusemos na seção anterior. Dentre as 18 repostas ao questionário, todas, em nível mais ou menos explícito, mobilizaram conceitos metafóricos. Há casos em que o Ensino Remoto Emergencial é conceptualizado em termos de doença, de distância geográfica, de viagem, de mercadoria etc. Percebemos, então, que trabalhar com a categoria metáfora conceptual se provou produtivo. Em termos numéricos, prova-se profícuo também trabalhar, de forma mais estrita, com a metáfora ERE É MERCADORIA, já que em 12 respostas essa modalidade de ensino é conceptualizada em termos de produto/artigo comercializável. É importante dizer que todos os respondentes do questionário fazem parte de um grupo que, em tese, não sofre de forma tão dura os impactos da mudança de modalidade educacional, pois boa parte deles são mestrandos e doutorandos, a outra parte é de graduandos e de professores, o que nos faz crer que, por já serem, em sua maioria, formados e estarem em idade adulta, o acesso ao maquinário e à tecnologia digital necessários ao acompanhamento das aulas e 
de outras interações educacionais sejam menos complicados, tanto pelo poder aquisitivo quanto pelo nível de letramento digital.

As mudanças no cenário educacional, provocadas pelo período de pandemia, exigem novas posturas. A forma de interagir em ambiente virtual é diferente da ação em situações presenciais de ensino, pois demanda outras competências, habilidades e performances. Por ser uma realidade diversa daquela com a qual estudantes e professores estavam acostumados a lidar, o ERE tem sido conceptualizado em termos também diversos daqueles que representam o ensino presencial. Como vamos observar nos dados a seguir, o Ensino Remoto Emergencial foi conceptualizado em termos de uma mercadoria precificável, o que significa dizer que, para além da pura descrição do ERE como um artigo de compra e venda, as ações e cenários construídos em torno dessa modalidade de ensino se estruturam, experiencialmente, em termos de uma transação mercadológica. Em outras palavras, frente ao ERE, a nossa experiência envolve aquilo que compreendemos como compra, venda, aquisição, investimento, ou seja, um tipo de relação comercial diretamente precificável ${ }^{14}$. Vejamos.

Os excertos a seguir dizem respeito às narrativas construídas a partir da provocação do exercício 'Se eu pudesse...'

Quadro 4 - Questionário ERE.

\begin{tabular}{|l|l|}
\hline Resposta 3 & $\begin{array}{l}\text { "teria uma internet descente, equipamentos adequados e tecnologia de } \\
\text { ponta." (sic) }\end{array}$ \\
\hline Resposta 4 & $\begin{array}{l}\text { "eu compraria uma parede verde, um equipamento de gravação, uma } \\
\text { internet sensacional e um projetor de holograma." }\end{array}$ \\
\hline Resposta 15 & $\begin{array}{l}\text { "... se eu pudesse ter um acesso melhor à internet, poderia me dedicar de } \\
\text { forma mais efetiva às aulas. A localidade em que moro não possui boa rede } \\
\text { de internet e, por esse motivo, já tive vários problemas para participar das } \\
\text { aulas." }\end{array}$ \\
\hline
\end{tabular}

Fonte: próprios autores.

14 Cabe remeter uma nota explicitando que, como já realçado anteriormente, essa conceptualização mercadológica sobre ensino e educação foi amplificada no período emergencial. Por outro lado, não se pode refutar que no ensino presencial os sujeitos envolvidos no processo de aprendizagem especulam sobre compra de livros, transporte e descolamentos, compra de roupas, lanches etc. Enfim, um trato também precificável quanto ao universo do fazer educacional. 
A provocação do exercício "Se eu pudesse" vai ao encontro da nossa proposta de observar os cenários projetivos construídos pelos estudantes e professores que aderiram ao Ensino Remoto Emergencial ${ }^{15}$. Essa proposta está em consonância com os dados jornalísticos coletados, já que tanto nas narrativas quanto nos discursos relatados, a conceptualização do ERE gira em torno do campo das possibilidades. Em um caso, por ser narrado sob uma perspectiva contrafactual, em outro, devido ao momento ser anterior à experiência factual nessa modalidade de ensino, por descrever o ERE em termos de projeções futuras.

Nas respostas citadas, as três narrativas construídas a respeito do Ensino Remoto Emergencial são estruturadas por meio de ações que revelam a construção de um cenário, qual seja: um tipo de compra e venda de produto relação comercial. Somos capazes de perceber, então, que os respondentes concebem o Ensino Remoto Emergencial como um tipo de investimento em um(s) produto(s). Isso fica evidente no modo como eles configuram suas ações como de compra e venda, ocupando lugar de cliente. Essas ações são coerentes com a concepção de que essa modalidade de estudos se estrutura de forma a haver clientes e vendedores, compra e venda, aquisição de certos produtos etc.

Em "teria uma internet descente, equipamentos adequados e tecnologia de ponta." (sic), o respondente constrói sua narrativa evidenciando que, sem investimento mínimo, não há condições de estudos. O processo de comoditização do ensino na modalidade remota digital é marcado pelos gastos na aquisição de diversos bens. Infraestrutura considerada adequada é um desses gastos, algo que está exposto nas ações que se configuram sob a perspectiva do ter. O respondente gostaria de

\footnotetext{
${ }^{15}$ Faz-se necessário mencionar que a proposição do ERE não foi uma questão opcional, mas, sim, uma necessidade. Compreendemos que a ausência do Ensino Remoto Emergencial converteria uma ação ainda mais devastadora. A pesquisa em questão busca colocar em cena problemas básicos/estruturais relativos à composição e operacionalização do ERE., de modo que se leve a reflexão essa modalidade de ensino.
} 
ter, ou seja, adquirir melhor internet e melhores equipamentos. Outro ponto que podemos observar, que coincide com os dados do domínio jornalístico, é que as construções das narrativas evidenciam aquilo que não se tem. Isso acontece para demonstrar a inadequação daquilo que se tem e, portanto, deve ser mudado/modificado. Fica claro que o uso da negação está relacionado com o fato de o enunciado do exercício propiciar a criação de cenários contrafactuais.

Outra narrativa que nos chama atenção pelo fato de conceber sua experiência de ensino no ERE é: "eu compraria uma parede verde, um equipamento de gravação, uma internet sensacional e um projetor de holograma.". Nessa construção, percebemos que a vivência educacional é completamente conceptualizada a partir de ações que revelam relações de compra. A projeção de um cenário diferente daquele vivido não rememora momentos pré-pandemia, com encontros e aulas presenciais, mas concebe o cenário que se vive como pouco modificável, atribuindo uma melhoria na situação ao ter acesso a bens e serviços que considera ideais, revelando, assim, a metáfora conceptual que subjaz ao discurso: ERE É MERCADORIA.

Em tempos de pandemia, temos visto que uma das principais formas de conceptualizar o ensino tem sido em termos de uma transação mercadológica, aquisição de um bem/serviço, por parte dos estudantes e professores; e lucro, por parte das operadoras de telefonia e internet, de fabricantes de eletroeletrônicos etc., mesmo que este segundo aspecto não seja tão falado. Quando os respondentes narram um tipo de experiência de ERE diferente da que está sendo vivida, eles vinculam esta experiência a investimentos financeiros em algum tipo de artigo de consumo relacionado ao acesso das aulas online. Assim, o que fica manifesto é que as narrativas são construídas de forma a evidenciar a maneira como as pessoas concebem a experiência do ERE como produto, e isso é feito tendo como base um processo metafórico que se estrutura por meio da metáfora ERE É MERCADORIA. Vejamos outros excertos. 
Quadro 5 - Questionário ERE.

\begin{tabular}{|c|c|}
\hline Resposta 7 & $\begin{array}{l}\text { “... se eu pudesse, estenderia a todos os estudantes do país a mesma } \\
\text { oportunidade que eu tive de continuar meus estudos na modalidade remota. } \\
\text { Todos os estudantes teriam internet de qualidade, até nos locais mais } \\
\text { longínquos do país. Teriam ferramentas tecnológicas de qualidade para que } \\
\text { pudessem acompanhar as aulas e realizar suas atividades sem transtornos ou } \\
\text { perdas. Que os professores de todas as escolas públicas fossem capacitados e } \\
\text { engajados para transpor as atividades, antes presenciais, para essa modalidade } \\
\text { de ensino, entretanto, isso só poderia ser possível, se eu pudesse primeiro, } \\
\text { transformar os políticos brasileiros em GENTE!” }\end{array}$ \\
\hline Resposta 8 & $\begin{array}{l}\text { "... viabilizaria o acesso ao ensino remoto para os alunos da rede pública, } \\
\text { principalmente para os alunos da educação básica. Essa seria uma tentativa } \\
\text { mínima de diminuir o abismo entre a rede pública e a rede particular de } \\
\text { educação, abismo este que tem aumentado neste período de pandemia, uma } \\
\text { vez que os alunos da rede pública não têm equipamentos e nem acesso à } \\
\text { internet e nada tem sido feito pelos órgãos "competentes". Se eu pudesse ainda, } \\
\text { agradeceria a todos os professores que têm se desdobrado e feito a diferença." }\end{array}$ \\
\hline Resposta 9 & $\begin{array}{l}\text { "Se eu pudesse, daria acesso remoto a todos os alunos que vivem em regiões } \\
\text { periféricas, ou distantes da zona urbana." }\end{array}$ \\
\hline Resposta 11 & $\begin{array}{l}\text { "Nesse confronto entre o que o governo e as escolas têm como tecnologia } \\
\text { disponível e o que os alunos de fato têm, fato é que quem sempre teve } \\
\text { melhores condições para estudar, continua no mesmo patamar durante a } \\
\text { pandemia". } \\
\text { "... não há como construir esse ambiente digital/social com equidade, pelo } \\
\text { menos não diante da discrepante desigualdade social vigente no país." }\end{array}$ \\
\hline
\end{tabular}

Fonte: próprios autores.

Nos excertos antes apresentados, somos capazes de perceber que as narrativas são construídas mobilizando concepções de ERE como intimamente ligadas ao poder aquisitivo daqueles que querem/precisam aderir a essa modalidade. Na resposta 7, "Todos os estudantes teriam internet de qualidade, até nos locais mais longínquos do país. Teriam ferramentas tecnológicas de qualidade para que pudessem acompanhar as aulas e realizar suas atividades sem transtornos ou perdas.", fica claro que o Ensino Remoto Emergencial pode ser garantido com investimento material/econômico na aquisição de serviços (internet) e materiais eletrônicos (celular, computador, tablet etc.) essenciais a essa modalidade de educação. 
Outro ponto latente deste último conjunto de narrativas é que o ERE é um produto majoritário das classes sociais com maior poder aquisitivo. Na resposta 11, a narrativa é construída de forma a lançar luz sobre as diferenças sociais: "fato é que quem sempre teve melhores condições para estudar, continua no mesmo patamar durante a pandemia.". O ERE ser concebido em termos de artigo vendável é evidenciado nesse excerto ao ser relacionado aos grupos que historicamente possuem mais estofo financeiro. Assim, o ERE É MERCADORIA de difícil acesso àqueles que têm menor poder de compra.

Condições paritárias são pouco factíveis, de acordo com as narrativas construídas, pois, ao conceptulizarem o ERE como MERCADORIA, os respondentes deixam claro que o ERE, em tempos de pandemia, tem sido um marcador de diferenças socioeconômicas. No excerto da $8^{\mathrm{a}}$ resposta, “...viabilizaria o acesso ao ensino remoto para os alunos da rede pública, principalmente para os alunos da educação básica. Essa seria uma tentativa mínima de diminuir o abismo entre a rede pública e a rede particular de educação, abismo este que tem aumentado neste período de pandemia, uma vez que os alunos da rede pública não têm equipamentos e nem acesso à internet e nada tem sido feito pelos órgãos "competentes" ", o Ensino Remoto Emergencial é concebido como um produto acessível aos alunos de escolas particulares e não acessível aos alunos de escolas públicas. Conceber o ERE como um produto estreitamente ligado a determinado público vai ao encontro da metáfora conceptual que subjaz às narrativas e relatos sobre a educação em tempos de pandemia: ERE É MERCADORIA.

Sob uma lógica mais ampla, o que fica claro é que, em última instância, a conceptualização de educação sofreu importantes modificações no período de pandemia. Compreendida como atividade pedagógica e didática, pautada, principalmente, em uma perspectiva processual, a educação passa a ser conceptualizada sob um viés prioritariamente mediado por telas em aparelhos eletrônicos, com produção unilateral de conteúdos, conformando-se, então, como 
entrega de um produto acabado, o que corrobora a nossa tese de que experienciamos o Ensino Remoto Emergencial em termos de compra/venda de um artigo.

\section{CONSIDERAÇÕES FINAIS}

Com o intuito de compreendermos de forma mais profunda a maneira como o ERE tem sido experienciado e narrado, optamos por propor uma investigação que nos permitiu observar aquilo que subjaz aos discursos e às narrativas acerca do Ensino Remoto Emergencial. Por esse motivo, decidimos agir em duas frentes a um só tempo, observando e analisando o seguinte: os discursos relatados coletados no jornal Folha de S. Paulo e as narrativas pessoais e subjetivas de indivíduos que aderiram ao ERE.

Em nosso rastreamento e análise da metáfora ERE É MERCADORIA, não conseguimos observar que as pessoas apenas falam sobre educação como se fosse um artigo precificável, mas suas ações e vivências frente à educação são configuradas em termos de mercadoria: as pessoas compram melhores aparelhos mediadores da experiência, pagam pela internet que propiciará melhor acesso às aulas, a aula é entregue como um produto acabado que independe da ação dos estudantes etc. Dessa forma, há um reforço da relação cliente-vendedor entre as partes envolvidas em uma transação mercadológica.

Trabalhar com discursos de âmbito privado e público, respectivamente, nos permitiu perceber o quão plausível se mostrou a nossa aposta de que o processo de conceptualização do ERE se estrutura metaforicamente, já que reflete diferentes domínios da vida humana, domínios de ordem mais micro e domínios de ordem mais macrossociais. Assim, nesses dois domínios, encontram-se as narrativas da experiência subjetiva (âmbito micro) e os discursos relatados/reportados, portanto, menos subjetivos (âmbito macro). Outro ponto que deve ser evidenciado é que esta estratégia, comparar discursos de ordem 
pública e privada, demonstra o fato de a metáfora ERE É MERCADORIA ser pervasiva, já que somos capazes de encontrá-la sistematicamente diversos tipos de discursos, descrevendo experiências e ações acerca do ensino em tempos de pandemia. Por fim, é necessário reforçar o fato de que, mais do que somente perceber o processamento metafórico que subjaz às narrativas e relatos sobre o ERE, intentamos observar se tal processamento se estrutura por meio de uma metáfora conceptual.

\section{REFERÊNCIAS}

BRASIL. Portaria $n^{\circ} 343$ de 17 de março de 2020. Dispõe sobre a substituição das aulas presenciais por aulas em meios digitais enquanto durar a situação de pandemia do Novo Coronavírus - COVID-19, Brasília, DF, Ministério da Educação, 2020. Disponível em: https://www.in.gov.br/en/web/dou/-/portaria-n-343-de-17-de-marco-de-2020248564376. Acesso em: 25 jun. 2020.

FREIRE. Educação como prática da liberdade. Rio de Janeiro: Paz e Terra, 1967.

HODGES, C. et al. The difference between emergency remote teaching and online learning. EDUCASE Review. (27 march) 2020. Disponível em: https://er.educause.edu/articles/2020/3/the-difference-between-emergency-remote teaching-and-online-learning. Acesso em: 31 ago. 2020.

KEEGAN, D. The Foundations of the Distance Education. London: Ed. Croom Helm, 1991.

LAKOFF, G.; JOHNSON, M. Metáforas da vida cotidiana. Tradução do Grupo de Estudos da Indeterminação e da Metáfora - GEIM. São Paulo: EDUC, Campinas (SP): Mercado de Letras, 2002.

LAKOFF, G.; JOHNSON, M. Metaphors We Live By. Chicago: University of Chicago Press, 1980.

SILVA, M. M. dos S. e. Metáforas de aprendizagem: um olhar sobre narrativas multimodais de aprendizes de língua inglesa. 2013. 115 f. Dissertação (Mestrado em Linguística Aplicada) Faculdade de Letras, Universidade Federal de Mina Gerais, Belo Horizonte.

REDDY, M. J. The conduit metaphor: a case of frame conflict in our language about language. In: ORTONY, A. Metaphor and Thought. Cambridge: Cambridge University Press, 1979. p. 284-297.

Nota do editor:

Artigo submetido para avaliação em: 11 de novembro de 2020.

Aprovado em sistema duplo cego em: 10 de fevereiro de 2021. 